\title{
Event Management for Sensing Enterprises with Decision Support Systems
}

\author{
Andrés Boza ${ }^{1}$ - M. M. E. Alemany ${ }^{1}$. \\ Llanos Cuenca ${ }^{1}$ - Angel Ortiz ${ }^{1}$
}

Received: 25 November 2014 / Revised: 31 March 2015 / Accepted: 6 April 2015 /

Published online: 17 April 2015

(C) Springer-Verlag Berlin Heidelberg 2015

\begin{abstract}
Sensing enterprises make use of new technologies to capture real-time information and fed constantly the decision making process. Decision support systems (DSS) are exposed to these real-time events and it is possible to start the decision process from scratch in case any unexpected internal and external events take place. Thus, an event monitoring and management system should interact with the DSS to manage events that might affect their decisions. It should act as a supra-system to identify when decisions made are still valid or need to be reanalysed. The traditional configuration of DSS (where they collect internal and external information of the organization and the decision-maker is involved in the decision-making process) should be extended to treat event management using a monitoring and management system, which monitors internal and external information and facilitate the introduction of no monitored events. This monitor and manager systems become more and more necessary due to the incessant incorporation of new technologies that enables the companies to be more context-sensitive. Furthermore, this new and/or more accurate information, which is obtained for the organization, requires a proper management.
\end{abstract}

Keywords Sensing enterprise - Decision support system · Decision-making · Event management

Andrés Boza

aboza@cigip.upv.es

M. M. E. Alemany

mareva@cigip.upv.es

Llanos Cuenca

1lcuenca@cigip.upv.es

Angel Ortiz

aortiz@cigip.upv.es

1 Research Centre on Production Management and Engineering (CIGIP), Universitat Politècnica de València, Camino de Vera S/N, 46022 Valencia, Spain 


\section{Introduction}

The decision-making process involves a choice from a number of alternatives. This process is usually a complex process, which involves resources and time consumption. As a result of this process an alternative is selected. Additionally, there is a natural tendency when a choice is made to reinforce the decision and to reduce the value of the other alternatives. This effect in the decision-making is produced by what is called cognitive dissonance: when we choose between two options, we unconsciously reduce the value of the rejected object [1].

Accordingly, it is difficult to contemplate a revision of the decisions once has been made due to (1) the complexity of the process, (2) the effect of considering the alternatives with a lower value and (3) the implications in the ongoing activities. It is possible to find examples in [2], they indicate that the production planning is a complex task which requires coordination between multiple areas of the organization, and the aggregation and disaggregation of information between various hierarchical levels. Also, [3] highlights the difficulties of adapting production plans for disturbances, rush orders or breakdowns, where often, no change are made.

And, what happens when decision support systems (DSS) are involved?

DSS help decision-makers to make decisions useful for a period of time. Many of these systems make decisions regularly with established timeframes and the decision process start at the end of each time period and use the information available at the beginning of each period. The effect described above also occurs in the decisionmaking process using DSS because these systems are usually rigid systems [3-5].

But, does it make sense to reconsider decisions with ongoing activities?

The answer seems to be simple: Whenever incorporating the review process and change the decision will be better than continuing with the current decision. However, putting this into practice has not been an easy issue. But, according to the Future Internet-based Enterprises (FInES) Cluster [6], the next decade is expected to see a thorough change in the way enterprises operate, mainly due to the advent of Future Internet and the maturity achieved by enterprises in adopting new socio-technical solutions based on the former.

And what can produce a change in our decisions?

As we noted above, the decision-making process is complex and DSS work with information obtained from the real situation of the company, but also work with projections that incorporate a certain level of uncertainty. When a projected scenario match with the actual situation then it is not necessary to redefine anything, but, it makes sense to consider reanalyse the decision when it does not match with the planned situation.

And, what does it mean that a projected scenario does not match with the actual situation?

Small variations may not be significant and hence it is not necessary to reanalyse the decision. However, significant changes or new items, not previously identified, with significantly influence in the decision may require reanalyse the decision. Here, the concept of events arises.

An event can be defined as an incident or occurrence that might evolve from either internal or external sources of operations within the network. It is identified as a devi- 
ation from an existing plan or occurrence. The negative impact of an event represents risk, which needs management assessment and response [7]. It is therefore, essential to identify a range of potential events in terms of positive or negative impact, which represent opportunities or risks [8]. The mentioned deviations can be in terms of time, quality, quantity, etc.

The FInES Cluster proposes 9 paradigmatic enterprise profiles concerning to the qualities of being (QB) of the Future Internet-based Enterprises. One of these profiles is being a Sensing Enterprise. In SE, the enterprise is seen as a smart complex entity capable of sensing and reacting to (business) stimuli.

Sensing enterprises enable this identification because sensing enterprises make use of the sensing possibilities provided by interconnected 'environments', anticipating future decisions by using multi-dimensional information captured through physical and virtual objects, and providing added value information to enhance its global context awareness [9]. However, this new information must be managed for intra-enterprises and inter-enterprises scenarios [10].

The main objective of event monitoring and management (EMM) is to inform relevant parties and manage any uneven situation that might cause serious damage to an industrial establishment. The EMM can be divided into two sections: event monitoring and the reactive efforts to an event occurrence. Event monitoring can be identified as a preliminary step toward event management, where an identification of the abnormalities (events) occurs. The reactive efforts to an event occurrence are measured in terms of deviation from an actual plan and the necessary planning is done to minimize its negative impact to an organization [7].

\section{Events and Decision Support System}

The original concept of DSS was defined by Gorry and Scott Morton in 1971, who integrated the classification of [11] about planning and control systems and the classification of [12] about decision types.

These decision types include scheduled decision problems (routine, repetitive, wellstructured, easy to solve) and unscheduled decision problems (new, unstructured, difficult to resolve). DSS field participates in this last type as a computerized system for semi-structured or unstructured decisions. A computer system could be developed to deal with the structured portion of a DSS problem, but the judgment of the decision-maker was brought to bear on the unstructured part, hence constituting a human-machine, problem-solving system [13].

Additionally, other systems interact with the DSS. Data Mining and Knowledge extract patterns from massive data sets for decision support [14].

From the operation point of view in a DSS, executions of DSS may be depending on the nature of decisions: these can be periodic with a temporal patron or no-periodicals executed according to the decision-maker criteria or by a dispatcher from other information system. In both cases, unexpected events may appear and it will be convenient to reconsider the decision. For example, hierarchical production planning systems face changes in the production process, rush orders or breakdowns, which would force to reassess the current plans. 
An example of these changes is found in the ceramic sector when amounts and types of finished product are different from the planned production due to uncontrolled factors during the manufacturing process, which should cause the rescheduling of deliveries, amounts committed or the master production schedule [15] and something similar happens in the food processing industries [3], where, one of the conclusions of their research is that potential benefits are lost because organizations do not know how to respond appropriately to unexpected events. These organizations do not properly manage events in hierarchical planning due to the hierarchical decision-making structure, where coordination between different levels (with frozen plans) is not always possible in a short period of time; however, they can have enough production capacity.

Also, the decision-maker may act regardless of the DSS when some events happen. [16] treat it as the descriptive perspective, which describe as the task is performed in practice (versus as should be formally performed) and it is not in the information system design.

Thus, despite the advantages of DSS, some of them also have drawbacks due to rigidity in the decision-making process. Therefore, the design of DSS should consider the event management, inside the DSS or using a supra-system to manage them.

\section{Event Management Systems and DSS}

One of the basic functionalities of event monitoring and management (EMM) systems is to notify the organizations about events as early as possible. For this reason, event monitoring and management require information systems. EMM provides enhanced support through an integrated IT-based solution. The conception and implementation of appropriated information and communication systems is a basic condition for the identification of critical incidents in operational process executions. An automated process to identify, monitor and control an event can vary significantly depending on the origin of the events. And, an automated event-detection system can offer a real-time view to the events [7]. Nowadays, new smart components are being developed for the sensing enterprises. These components may be sensors, tags, intelligent agents, smart objects, etc. enabling a continuous awareness and improvement of business operations in a digital environment that will bring new business trends and models not possible otherwise [17].

But an event monitoring and management system is more than an event-detection system. It is necessary to sort or classify the events according to their impact and likelihood levels, implement different prioritization policies when dealing with queues of incidents, describe the notification process according to the level of urgency of each event, assign the incident to the most appropriate support person/group/system or manage the incident lifecycle [7,18,19].

Thus, it is possible to identify two main objectives of the event management process. The main objective is to prevent the future occurrences of an event through proper managerial decision or attention [7], this effort may be expensive and not easy to prevent it depending on the event. Then, a second objective for a shorter period of time is to manage the event occurrences when they appear [20].

Hence, the DSS systems are exposed to events from any decision level of the company and it is possible to start the decision process from scratch in case any 


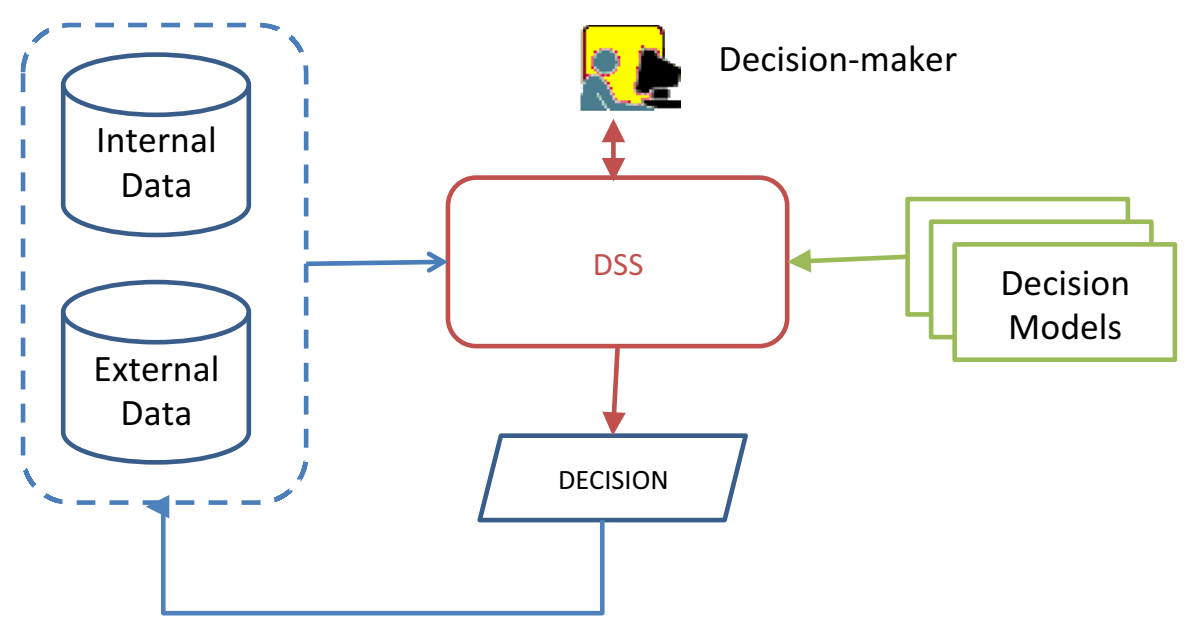

Fig. 1 Traditional DSS configuration

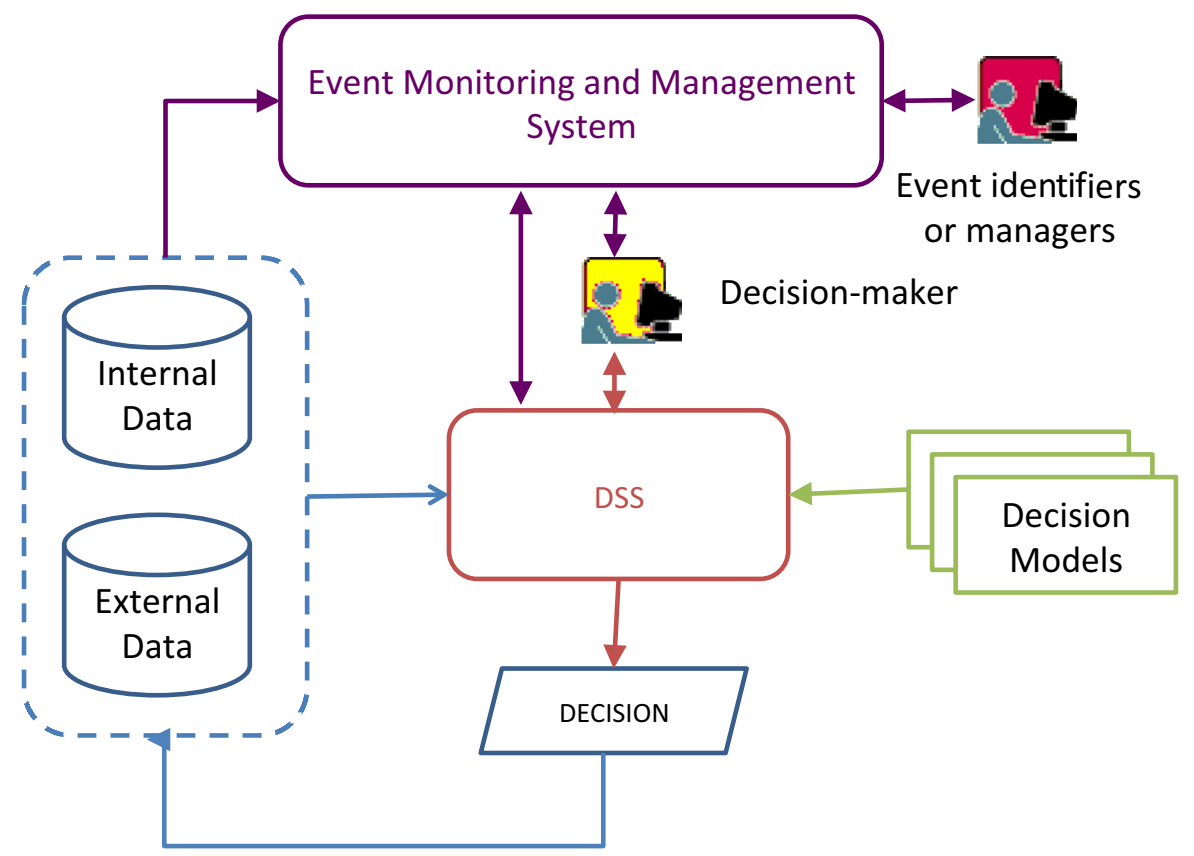

Fig. 2 DSS and event monitoring and management system

unexpected internal and external events take place [5]. Also, it is possible a hierarchical approach to this decision context, where the coordination between decision activities in strategic, tactical and operative levels is made according to a hierarchical structure. This means that each one will pursue its own goals, but always considering those of upper levels, on which they depend, and those of lower levels, at which they restrict [21]. Thus, re-planning at higher levels must involve a cascade of new re-planning processes 
in the lower decision levels. But, decisions with DSSs are taken in a centralized fashion, in a hybrid control models or in a decentralized fashion [22], which adds complexity to manage events.

Thus, an event monitoring and management system should interact with the DSS to manage events that might affect their decisions. It should act as a supra-system to identify when decisions made are still valid or need to be reanalysed. Therefore, the traditional configuration of DSS (where they collect internal and external information of the organization and the decision-maker is involved in the decision-making process, Fig. 1) should be extended to treat event management using a monitoring and management system which monitors internal and external information and facilitate the introduction of no monitored events (because it is a new type of event or because it is an event not managed by their internal and external information systems) (Fig. 2).

\section{Conclusions}

Decisions are made using current information and assumptions and they are valid while these information and assumptions remain. DSS are often not permeable to changes in the environment, which can invalidate its decisions. Nowadays, these changes in the environment are detected more quickly and precisely owing to the fact that new technologies are arising around the sensing enterprise concept. This monitor and manager systems become more and more necessary due to the incessant incorporation of these new technologies that enables the companies to be more context-sensitive. Furthermore, this new and/or more accurate information, which is obtained for the organization, requires a proper management.

Thus, using event monitoring and management system is a requirement to adjust decisions with the real situation in the company. Also, DSS should be developed taking into account the new proposals in the sensing enterprise field in order to be more sensitive to its context.

Acknowledgments This research has been carried out in the framework of the project PAID-0621Universitat Politècnica de València (Sistema de ayuda a la toma de decisiones ante decisiones no programadas en la planificación jerárquica de la producción) and GV/2014/010 Generalitat Valenciana (Identificación de la información proporcionada por los nuevos sistemas de detección accesibles mediante internet en el ámbito de las "sensing enterprises" para la mejora de la toma de decisiones en la planificación de la producción).

\section{References}

1. Estupinyà $P$ (2010) El ladrón de cerebros: Compartiendo el conocimiento científico de las mentes más brillantes. Penguin Random House Grupo Editorial España

2. Vicens E, Alemany ME, Andrés C, Guarch JJ (2001) A design and application methodology for hierarchical production planning decision support systems in an enterprise integration context. Int $\mathbf{J}$ Prod Econ 74:5-20. doi:10.1016/S0925-5273(01)00103-7

3. Van Wezel W, Van Donk DP, Gaalman G (2006) The planning flexibility bottleneck in food processing industries. J Oper Manag 24:287-300. doi:10.1016/j.jom.2004.11.001

4. Winter R (1994) Multi-stage production controlling based on continuous, flexible abstraction hierarchies. IEPM 
5. Özdamar L, Bozyel MA, Birbil SI (1998) A hierarchical decision support system for production planning (with case study). Eur J Oper Res 104:403-422. doi:10.1016/S0377-2217(97)00016-7

6. FInES FIESC (2012) FInES Research Roadmap 2025

7. Shamsuzzoha Ah, Rintala S, Cunha PF, Ferreira PS, Kankaanpää T, Maia Carneiro L (2013) Event monitoring and management process in a non-hierarchical business network. In: Poler R, Carneiro L, Jasinski T, Zolghadri rc, Pedrazzoli P (eds) Intelligent non-hierarchical manufacturing networks. Wiley, New York, pp 349-374

8. Committee of Sponsoring Organizations of the Treadway Commission (2004) COSO enterprise risk management-integrated framework: application techniques. Committee of Sponsoring Organizations of the Treadway Commission

9. Santucci G, Martinez C, Vlad-Câlcic D (2012) The sensing enterprise. FInES workshop at FIA 2012

10. Vargas A, Cuenca L, Boza A, Sacala I, Moisescu M (2014) Towards the development of the framework for inter sensing enterprise architecture, J Intell Manuf, 1-18

11. Anthony RN (1965) Planning and control systems: a framework for analysis. Harvard University, Cambridge

12. Simon HA (1960) The new science of management decision. Harper \& Brothers, New York

13. Shim JP, Warkentin M, Courtney JF, Power DJ, Sharda R, Carlsson C (2002) Past, present, and future of decision support technology. Decis Support Syst 33:111-126. doi:10.1016/S0167-9236(01)00139-7

14. Peng Y, Kou G, Shi Y, Chen ZA (2008) Descriptive framework for the field of data mining and knowledge discovery. Int J Inf Technol Decis Mak 7:639-682. doi:10.1142/S0219622008003204

15. Alarcón F, Alemany MME, Lario FC, Oltra RF (2011) La falta de homogeneidad del producto (FHP) en las empresas cerámicas y su impacto en la reasignación del inventario. Boletín de la Sociedad Española de Cerámica y Vidrio 50:49-58. doi:10.3989/cyv.072011

16. Cegarra J, van Wezel W (2011) A comparison of task analysis methods for planning and scheduling. In: Fransoo JC, Waefler T, Wilson JR (eds) Behavioral operations in planning and scheduling. Springer, Berlin Heidelberg, pp 323-338

17. FP7-ICT (2012) ICT: Information and Communication Technologies: work programme 2013

18. Barash G, Bartolini C, Wu L (2007) Measuring and improving the performance of an IT support organization in managing service incidents. In: 2nd IEEE/IFIP international workshop on businessdriven IT management, BDIM '07, pp 11-18

19. Bartolini C, Stefanelli C, Tortonesi M (2010) SYMIAN: analysis and performance improvement of the IT incident management process. IEEE Trans Netw Serv Manag 7:132-144. doi:10.1109/TNSM. 2010.1009.I9P0321

20. Boza A, Alemany MME, Alarcón F, Cuenca L (2013) A model-driven DSS architecture for delivery management in collaborative supply chains with lack of homogeneity in products. Prod Plan Control 25:650-661. doi:10.1080/09537287.2013.798085

21. Boza A, Ortiz A, Vicens E, Poler R (2009) A framework for a decision support system in a hierarchical extended enterprise decision context. In: Poler R, van Sinderen M, Sanchis R (eds) Enterprise interoperability. Springer, Berlin Heidelberg, pp 113-124

22. Grefen P, Dijkman R (2013) Hybrid control of supply chains: a structured exploration from a systems perspective. Int J Prod Manag Eng 1:39-54 